\title{
PLATAFORMAS DIGITALES DE RESERVAS HOTELERAS, ACCIONES ACUMULATIVAS Y SU IMPACTO EN LA ESTRATEGIA DE LITIGACIÓN INTERNACIONAL. COMENTARIO A LA SENTENCIA DEL TJUE DE 24 DE NOVIEMBRE DE 2020, C-59/19, WIKINGERHOF VS. BOOKING
}

\author{
ONLINE ACCOMODATION BOOKING PLATFOMS, \\ ACCUMULATION OF OBLIGATIONS AND ITS IMPACT \\ ON THE STRATEGY OF INTERNATIONAL LITIGATION. \\ COMMENTARY TO THE ECJ JUGMENTOF 24 \\ NOVEMBER2020, C-59/19, WIKINGERHOF VS. BOOKING
}

\author{
ISABEL ANTÓN JUÁREZ \\ Profesora titular acr. de Derecho internacional privado \\ Universidad Carlos III de Madrid \\ ORCID ID: 0000-0002-5639-2301
}

Recibido: 15.01.2021 / Aceptado: 23.01.2021

DOI: https://doi.org/10.20318/cdt.2021.5983

\begin{abstract}
Resumen: El objetivo de este trabajo es analizar la STJUE de 24 de noviembre de 2020. Este caso refleja muy bien los límites que existen entre lo que se puede considerar una materia contractual y extracontractual en atención al Reglamento UE 1215/2012 y el impacto que puede presentar tal calificación en la litigación transfronteriza. El objeto del presente artículo no persigue estudiar de forma exhaustiva los arts. 7.1 y art. 7.2. El objetivo es más bien que en base a esta resolución del TJUE poder esbozar unas líneas sobre los aspectos relevantes que se deben tener en cuenta en la organización de una estrategia de litigación internacional en los asuntos en los que se reclama responsabilidad civil extracontractual entre partes contratantes que tienen que ver con la aplicación privada de las normas de competencia.
\end{abstract}

Palabras clave: plataformas de reservas de hoteles, responsabilidad extracontractual, daños, litigación internacional, abuso de posición de dominio, R. Bruselas I bis.

Abstract: The aim of this paper is to study the ECJ resolution of 24 November 2020. This case shows very good the fine line between the contractual and non-contractual matter according to the Brussels I bis Regulation and the impact of such classification on the international litigation. The objective of this article is not study exhaustively arts. 7.1 and 7.2. On the contrary, we will try to outline some important considerations to organice a good strategy in an international litigation regardinf private enforcement having as a reference this ECJ resolution.

Keywords: online accomdation booking platform, non-contractual liability, damages, international litigaction, abuse of dominant position, Brussels I bis Regulation

Sumario: I. Introducción. II. Hechos del caso. III. La calificación de la acción en Wikingerhof vs. Booking. IV. Consideraciones jurídicas relevantes de este asunto desde el punto de vista de la litigación transfronteriza. 1. Introducción. 2. Acciones acumulativas y su impacto en la determinación del tribunal competente. 3. Acciones paralelas y litispendencia. V. Conclusiones. 


\section{Introducción}

1. El objeto del presente trabajo es el análisis de la STJUE de 24 de noviembre de 2020 en la que el Bundesgerichtshoft (Tribunal Supremo alemán) remite una cuestión prejudicial en relación a un asunto que enfrenta a un hotel con la famosa plataforma de reserva de hoteles Booking ${ }^{l}$.

2. En esencia, el TJUE con esta resolución debe resolver si el art. 7.2 del Reglamento UE $N^{o}$ 1215/2012 del Parlamento Europeo y del Consejo de 12 de diciembre de 2012 relativo a la competencia judicial internacional y ejecución de resoluciones judiciales en materia civil y mercantil (en adelante, R. Bruselas I bis) es un foro que permitiría conocer a un tribunal alemán de una acción que persigue que Booking cese de realizar determinados actos enmarcados dentro de una relación contractual y que implicarían según el demandante actos abusivos contrarios a las normas alemanas de competencia.

3. Esta sentencia plantea distintas cuestiones jurídicas dignas de interés, estas serían las siguientes:

1) Diferencia entre materia contractual y extracontractual en atención al art. 7.1 y 7.2 R. Bruselas I bis.

2) Las acciones acumulativas y cómo pueden influir en la determinación del tribunal competente y en otras cuestiones relativas a la estrategia procesal a seguir en asuntos que afectan Derecho internacional privado europeo relativos a la prueba y a la pendencia del proceso.

\section{Hechos del caso}

4. Wikingerhof, hotel situado en Kropp, población situada al norte de Alemania, firmó en 2009 un contrato tipo que le permitiría aparecer en la plataforma on line hotelera Booking ${ }^{2}$ con domicilio en Países Bajos.

Esas condiciones generales de contratación fueron modificadas varias veces por Booking. Sin embargo, en 2015, Wikingerhof se negó a seguir aceptando las condiciones contractuales que le imponía Booking. El hotel alemán consideró que debido a la posición de poder de Booking en el mercado, ésta abusaba de su poder infringiendo las normas de competencia alemanas. Esto llevó a Wikingerhof a interponer una acción de cesación ante los tribunales alemanes de Kiel. En base a esa acción, el hotel alemán perseguía que Booking dejara de hacer lo siguiente ${ }^{3}$ :

1) De indicar en su plataforma la expresión "precio más reducido o "”precio más económico" junto al precio determinado sin el consentimiento de Wikingerhof.

2) De impedir que Wikingerhof tuviera acceso a los datos de contacto que los clientes de su hotel facilitan mediante Booking al hacer la reserva.

3) De supeditar el posicionamiento del hotel en la plataforma en base a la concesión de una comisión superior al 15\%.

5. Sin embargo, la situación se complicó para Wikingerhof. Tanto en primera como en segunda instancia, los tribunales alemanes consideraron que no tenían competencia en base al foro del art. 7.2 del R. Bruselas I $b i s^{4}$. El tribunal de primera instancia (el Landgericht de Kiel) entendía que la competencia judicial internacional y territorial era a favor de los tribunales de Ámsterdam debido a un acuerdo de sumisión expresa que se recogía en las condiciones generales de contratación. En base a otro razonamiento pero con el mismo resultado, el tribunal de apelación (Oberlandesgericht Schleswig) consideró que la

\footnotetext{
${ }^{1}$ STJUE 24 noviembre 2020, Wikingerhof v. Booking, C- 59/19, ECLI:EU:C:2020:950.

${ }^{2}$ Conclusiones del Abogado General Sr. H. Saugmandsgaard Øe, presentadas el 10 de septiembre de 2020. Wikingerhof GmbH \& Co. KG contra Booking.com BV, ECLI:EU:C:2020:688, apartado 1.

${ }^{3}$ Ibidem, apartado 12.

${ }^{4}$ STJUE 24 noviembre 2020, Wikingerhof v. Booking, C- 59/19, ECLI:EU:C:2020:950, apartados 11 y 12.
} 
competencia era a favor de tribunales holandeses en atención al foro especial en materia contractual que se recoge en el art. 7.1 del R. Bruselas I bis.

6. Al contrario de lo que se pudiera pensar, Wikingerhof no se dio por vencido e interpuso un recurso de casación ante el Tribunal Supremo alemán (Bundesgerichthof) alegando la aplicación del art. 7.2 del R. Bruselas I bis. En base a este foro, el tribunal competente es el del lugar donde se ha producido el daño, es decir, el tribunal de Kiel, lugar donde el Wikingerhof sufre las prácticas abusivas de Booking. El TJUE señala que el tribunal remitente de la cuestión prejudicial no plantea la incidencia que podría tener en el asunto el acuerdo que atribuye competencia a los tribunales de Ámsterdam ${ }^{5}$. Esto es así debido a que dicho acuerdo no se celebró válidamente en atención al art. 25 del citado R. Bruselas I bis.

7. Por tanto, sobre lo que se debía pronunciar el TJUE es si sería de aplicación el art. 7.2 del R. Bruselas I bis para hacer competente a los tribunales alemanes en relación a una acción de cesación que está relacionada con determinados actuaciones que tienen que ver con una relación contractual existente entre Wikingerhof y Booking pero que al mismo tiempo el demandante (Wikingerhof) considera que dichas cláusulas contractuales le han sido impuestas, pudiendo constituir tales prácticas de Booking un abuso de posición de dominio.

La cuestión es que la acción que ejercita el hotel alemán no requiere sólo la interpretación del contrato, ya que el demandante alega que debido a ese abuso de posición de dominio de Booking, tales condiciones contractuales fueron impuestas implicando infracción de las normas de competencia. En definitiva, se debe calificar esa acción de responsabilidad civil entre partes contratantes.

De este modo, la clave está en la calificación que reciba de dicha acción que plantea Wikingerhof en lo relativo a la determinación de la competencia judicial internacional en base al R. Bruselas I bis. Si la misma se califica como una cuestión contractual, el foro que determinará el tribunal competente será el que se recoge en el art. 7.1 del R. Bruselas I bis, lo que implicaría que fueran competentes los tribunales del lugar del cumplimiento de la obligación litigiosa, es decir, tribunales holandeses. A sensu contrario si dicha acción se califica como una acción en materia extracontractual, una acción que tiene que ver con la aplicación privada del Derecho de la competencia europeo ${ }^{6}$, el foro de aplicación sería el que se establece en art. 7.2 del R. Bruselas I bis. Este foro otorgaría competencia a los tribunales del lugar donde se ha producido el daño, en materia de abuso de posición de dominio serían los tribunales alemanes, ya que son los tribunales del mercado afectado por el comportamiento supuestamente abusivo ${ }^{7}$.

El TJUE ya se ha pronunciado sobre la posibilidad de que el art. 7.2 pueda ser aplicado en este tipo de reclamación por daños ${ }^{8}$, ya que la Directiva que existe sobre la aplicación privada del Derecho

\footnotetext{
${ }^{5}$ Sobre el impacto que tiene un acuerdo de sumisión expresa en el foro especial en materia extracontractual vid. STJUE 24 octubre 2018, C-595/17, Apple Sales International y otros, ECLI:EU:C:2018:85. Esta sentencia ha sido muy comentada por la doctrina vid ad. ex. P.J. Buesogulllén, "Cláusulas de sumisión a fuero y ejercicio de acciones de daños y perjuicios de-rivados de ilícitos 'antitrust'. A propósito del As. C-595/17 Apple vs. MJA”, en J.I. Ruiz Peris/T. PalomarteJedor, Problemas actuales en las acciones de compensación de daños por infracción de las normas de competencia, Cizur Menor (Navarra), Thomson Reuters Aranzadi, 2019, pp. 55-76; A.L. Calvo Caravaca/J. Suderow, "Aplicabilidad de un acuerdo de elección de foro a una reclamación de daños por vulneración del artículo 102 TFUE: EL CASO Appel Sales International (C-595/17)", CDT, vol. 11, $\mathrm{n}^{\circ}$ 2, pp. 439-451; P. MANKOWSKI, "Rei-chweite von Gerichtsstandsvereinbarungen - kartellrechtliche Schadensersatzklage", Juristenzeitung, 2019, pp.141-144; P. PARADELA AREÁn, "La eficacia de las cláusulas jurisdiccionales en la aplicación privada del Derecho de la competencia: Sentencia del Tribunal de Justicia de 24 de octubre de 2019, asunto C-595/17: Apple Sales International y otros", La Ley Unión Europea, no 67, febrero 2019.

${ }^{6}$ Sobre este particular en la doctrina per alia A.L. Calvo Caravaca/J. Carrascosa González, "El Derecho Internacional privado de la Unión Europea frente a las acciones por daños anticompetitivos", $C D T$, vol. 10, n 2, pp. 7-178.

${ }^{7}$ Sobre este foro sin carácter exhaustivo vid. J. SuDERow, "Acciones derivadas de ilícitos antitrust: el foro especial de la obligación extracontractual después de la sentencia CDC Hidrogen Peroxide”, CDT, vol. 8, n 2, 2016, pp. 306-329.

${ }^{8}$ Vid. STJUE 23 octubre 2014, C-302/13, flyLAL-Lithuanian Airlines, ECLI:EU:C:2014:2319, apartados 23-29 y STJUE 29 julio 2019, C-451/18, Tibor-Trans, EU:C:2019:635, apartado 24. Para comentarios sobre esta última vid. C. KRÜGER, "Zur internationalen Zuständigkeit am 'Ort, an dem das schädigende Ereignis eingetreten ist' bei Kartellschäden ('Tibor-Trans')”, Entscheidungen zum Wirtschaftsrecht, 2019, pp. 769-770.; L. RADEMACHER, “Quieta Movere- pero no en silencio, por favor: EL TJUE sobre la competencia internacional en las acciones ilícitas derivados de ilícitos antitrust (Tibor-Trans,C-451/18)”, CDT, Vol, 12, nº 1, 2020, pp. 673-678.
} 
antitrust (Directiva 2014/104/UE del Parlamento Europeo y del Consejo de 26 de noviembre de 2014, relativa a determinadas normas o las que se rigen las acciones por daños en virtud del Derecho nacional, por infracciones del Derecho de la competencia de los Estados miembros y de la Unión Europea ${ }^{9}$ ) no regula ni cuestiones de competencia judicial internacional ni de Ley aplicable.

\section{La calificación de la acción en Wikingerhof vs. Booking}

8. El TJUE recuerda que la competencia general del R. Bruselas I bis se establece en atención al art. 4.1, foro que permite que ostenten competencia judicial internacional los tribunales del domicilio del demandado ${ }^{10}$. Los foros que se establecen en los arts. 7.1 y 7.2 del R. Bruselas I bis son foros especiales, foros que brindan una oportunidad extra al demandante a la hora de litigar, resultando uno de sus aspectos esenciales la proximidad que presentan con el litigio.

9. Esa calificación de la acción de si la misma se enmarca dentro de la "materia contractual" o "materia delictual" la debe realizar el demandante sin tener presente el Derecho nacional ${ }^{11}$. El TJUE ha sostenido en diferentes ocasiones como estos conceptos deben interpretarse de forma autónoma ${ }^{12}$, teniendo muy presente los objetivos y sistema del Reglamento ante la ausencia de un concepto legal en su propio texto.

Sin embargo, esta situación es compleja, prueba de ello es la numerosa jurisprudencia sobre este particular ${ }^{13}$. Especialmente esta dificultad aparece cuando determinadas acciones presentan diferentes calificaciones conforme al Derecho nacional del Estado donde se interpone la demanda ${ }^{14}$ o simplemente hay acciones que no se pueden calificar ni como "materia contractual" ni como "materia delictual"15.

10. De este modo, para calificar una acción dentro del radio de acción del art. 7.1 o del art. 7.2 se tiene que tener en cuenta la causa que sirve de base a esa pretensión ${ }^{16}$.

El art. 7.1 del R. Bruselas I bis será el foro que determinará la competencia judicial internacional si la interpretación del contrato que vincula al demandante con el demandado es el aspecto crucial y necesario que va a determinar si el comportamiento que se le reprocha al demandado es lícito o ilícito ${ }^{17}$.

Así, el art. 7.2 resultará de aplicación en los supuestos en los que el demandante invoca una norma de responsabilidad extracontractual impuesta por la ley, siendo la interpretación del contrato no indispensable para apreciar la licitud o ilicitud del comportamiento que se le reprocha al demandado ${ }^{18}$.

\footnotetext{
${ }^{9}$ DOUE L 349 de 5 de diciembre de 2014.

${ }^{10}$ STJUE 24 noviembre 2020, Wikingerhof v. Booking, C- 59/19, ECLI:EU:C:2020:950, apartado 21.

${ }^{11}$ STJUE 27 septiembre 1988, Kalfelis, C-189/87, ECLI:EU:C:1988:459, apartado 16.

${ }^{12}$ STJUE 17 de septiembre 2002, Tacconi, C-334/00, EU:C:2002:499, apartado 19;STJUE 18 Julio 2013, C-147/12, ÖFAB, EU:C:2013:490, apartado 27.

${ }^{13}$ En relación a la $<<$ materia contractual $>>$ vid. STJUE 22 de marzo 1983, Peters Bauunternehmung as-34/82, ECLI:EU:C:1983:87;STJUE 4 de octubre de 2018, Feniks, C-337/17, ECLI:EU:C:2018:80. En relación a la "materia delictual”, vid. STJUE 27 septiembre 1988, Kalfelis, C-189/87, ECLI:EU:C:1988:459;STJUE 17 de octubre 2017, Bolagsupplysningen e Ilsjan, C-194/16, ECLI:EU:C:2017:766.

${ }^{14} \mathrm{Ad}$ ex. este podría el caso de la culpa in contrahendo, la cual se califica como una cuestión contractual conforme al Derecho francés, sin embargo, conforme al Derecho alemán se califica como una cuestión extracontractual, tal y como apunta A. CEBrián SALVAT, "Estrategia procesal y litigación internacional en la Unión Europea: distinción entre materia contractual y extraconctractual”, $C D T$, Vol. 6, n 2, 2014, p. 320.

${ }^{15}$ Vid. Conclusiones del Abogado General Sr. H. Saugmandsgaard Øe, presentadas el 10 de septiembre de 2020. Wikingerhof GmbH \& Co. KG contra Booking.com BV, ECLI:EU:C:2020:688, apartado 47.

${ }^{16}$ STJUE 24 noviembre 2020, Wikingerhof v. Booking, C- 59/19, ECLI:EU:C:2020:950, apartado 31.

${ }^{17}$ STJUE 24 noviembre 2020, Wikingerhof v. Booking, C- 59/19, ECLI:EU:C:2020:950, apartado 32. En el mismo sentido anteriormente vid. STJUE de 13 de marzo de 2014, Brogistter, C-548/12, ECLI:EU:C:2014:148. Para un comentario de esta resolución vid. sin carácter exhaustivo M.Brosch, "Die Brogsitter-Defence: Neues zur Annexzuständigkeit am Vertragsgerichtsstand für deliktische Ansprüche in der EuGVVO, zugl Anmerkung zu EuGH 13. 3. 2014, C548/12, Marc Brogsitter/ Fabrication de Montres Normandes EURL und Karsten Fräßdorf”, ÖJZ, 2015, pp. 958-960; A. CebriÁn Salvat, "Estrategia procesal... op cit, pp. 315-329.

${ }^{18}$ STJUE 24 noviembre 2020, Wikingerhof v. Booking, C- 59/19, ECLI:EU:C:2020:950, apartado 33.
} 
11. En el asunto que nos ocupa, Wikingerhof y Booking tienen una relación contractual. Sin embargo, el hotel alemán imputa a la plataforma actuaciones abusivas debido a la posición de poder que ocupa en el mercado. Un tribunal que conozca de esta acción deber tener presente ese contrato que une a Wikingerhof y Booking. No obstante, el contrato no es un aspecto indispensable para determinar si Booking está infringiendo las normas de competencia, para ello se deberá acudir a las normas de competencia europeas sobre abuso de posición de dominio (art. 102 TFUE) o a las normas nacionales alemanas en materia de competencia.

Por lo tanto, el TJUE considera que la acción que entabla Wikingerhof puede quedar perfectamente enmarcada dentro del ámbito de aplicación del art. 7.2 R. Bruselas I bis ${ }^{19}$. Esto haría que fueran competentes los tribunales alemanes, tribunales del lugar del daño, los tribunales del mercado afectado por la supuesta conducta abusiva.

\section{Consideraciones jurídicas relevantes de este asunto desde el punto de vista de la litigación transfronteriza}

\section{Introducción}

12. La STJUE que comentamos aborda como cuestión primordial esa diferenciación entre materia contractual y delictual en atención al R. Bruselas I bis, que llevaría a aplicar en base a esa calificación bien el art. $7.1 \mathrm{o}$ el art. 7.2 del citado Reglamento.

Sin embargo, junto con esa cuestión jurídica hay otros tres aspectos interesantes que este tipo de asuntos pone en relieve y consideramos necesario analizar, estos serían: 1) las acciones acumulativa y su impacto en la determinación de la competencia judicial internacional; 2) la prueba que debe realizar el demandante; 3) la posibilidad de activar la litispendencia cuando se ejercitar acciones de doble naturaleza en tribunales de Estados miembros diferentes.

\section{Acciones acumulativas y su impacto en la determinación del tribunal competente}

\section{A) Planteamiento del problema jurídico}

13. Uno de los aspectos que pueden causar más dificultades a un juez al momento de determinar si ostenta competencia judicial internacional bien mediante el foro del art. $7.1 \mathrm{o} \mathrm{del} \mathrm{art.} 7.2 \mathrm{en}$ un asunto donde se reclama responsabilidad civil entre partes contratantes es cuando se trata de acciones acumulativas ${ }^{20}$. Es decir, acciones donde concurren diferentes obligaciones o responsabilidades al mismo tiempo. Esto sucede en el asunto objeto de comentario pero también se puede apreciar en otros muchos asuntos. En particular, uno de ellos podría tener lugar en determinados contratos de distribución en los supuestos en los que el proveedor se niega a seguir suministrando a su distribuidor. Escenarios que han sido habituales para evitar el comercio paralelo de productos farmacéuticos ${ }^{21}$.

Esta negativa en el suministro puede generar legalmente dos tipos de responsabilidades, estas serían: 1) un incumplimiento del contrato de distribución; 2) una infracción de las normas de competen-

\footnotetext{
${ }^{19}$ STJUE 24 noviembre 2020, Wikingerhof v. Booking, C- 59/19, ECLI:EU:C:2020:950, apartado 36.

${ }^{20}$ Estas cuestiones ya han sido objeto de estudio por la doctrina internacional privatista vid. ad. ex. S. Bolle, "La responsabilité extracontractuelle du contractant en droit internacional privé" en D. BuREAu/H.MuIR-Watt, Mélanges en l'honneur du professeur Bernard Audit - Les relations privées internationales, LGDJ, 2014, pp. 119-135; S. ZoGG, "Accumulation of contractual and tortious causes action under the judgments regulation", Journal of Private International Law, vol. 9, $\mathrm{n}^{\circ} 1$, 2013, pp. 39-76.

${ }^{21}$ I.Antón JuÁrez, La distribución y el comercio paralelo en la Unión Europea, La Ley, Madrid, pp. 377 y ss. C. Desogus, Competition and innovation in the EU regulation of phamarceuticals: the case of parallel trade, Cambridge, Antwerp, Insertia, 2011; A. GARCía VIDAL, "El comercio paralelo de medicamentos", CDT, vol. 5, nº 2, 2013, pp. 315-334, en concreto pp. 320 a 325.
} 
cia. En particular, se podría infringir el art. 102 TFUE cuando la empresa que realiza esa negativa en el suministro tiene una posición de poder en el mercado de referencia ${ }^{22}$.

14. Por lo tanto, en el contexto en el que nos encontramos de precisar la competencia en virtud de los foros especiales en "materia contractual" (art. 7.1) o en "materia delictual" (art. 7.2), el juez nacional que tuviera que conocer de la acción que interpone el distribuidor afectado debería proceder a la calificación de esa obligación en la que se sustenta la acción del demandante. El problema que plantean este tipo acciones judiciales al igual que sucedía en el asunto objeto de comentario es que esa acción que se interpone por el demandante puede presentar concurrencia de responsabilidades.

15. Este tipo de acciones además presentan una complicación y es que hay ordenamientos que permiten que cuando una acción acumula responsabilidad contractual y también extracontractual que el demandante pueda elegir cómo enfocar la demanda. De este modo, en estos Derechos nacionales, el demandante, en atención a sus intereses puede plantear el litigio desde la perspectiva contractual o extracontractual o incluso acumular ambas pretensiones en una misma acción. Este es el caso del Derecho alemán o del Derecho inglés ${ }^{23}$. Sin embargo, hay otros ordenamientos como el francés donde el margen de acción del demandante es escaso, prevaleciendo las cuestiones contractuales frente a las de responsabilidad extracontractual ${ }^{24}$. En el ordenamiento jurídico español, el TS ha considerado que es posible la yuxtaposición de responsabilidades lo que permite que se puedan ejercer acciones de diferente naturaleza de forma alternativa y subsidiariamente. Así, el demandante puede optar por reclamar ambas responsabilidades al mismo tiempo o declinarse sólo por una, siempre con el fin de que la víctima pueda ver resarcido su daño de la forma más completa posible ${ }^{25}$.

\section{B) Solución}

16. Una de las primeras máximas que llevan a solucionar este problema jurídico es que no hay prevalencia de lo contractual frente a lo delictual en base al sistema de foros del R. Bruselas I bis ${ }^{26}$. Ambos son foros alternativos al foro del domicilio del demandado y se encuentran en el mismo nivel de jerarquía.

17. Por lo tanto, la solución es que las acciones se deben analizar de forma individual y en atención a la causa por la que se invocan, a su fundamento ${ }^{27}$. De este modo, volviendo al ejemplo del proveedor que niega el suministro al distribuidor, en este tipo de asuntos donde pueden concurrir responsabilidades, las pretensiones se analizan de forma separada para que se puedan calificar como "materia contractual" o "delictual" y así el juez pueda precisar su competencia para la acción que plantea el demandante bien en base al art. $7.1 \mathrm{o}$ al art. 7.2 del R. Bruselas I bis.

Como se ha precisado en la sentencia objeto de comentario, para calificar esa obligación como "materia contractual" se deberá apreciar si el contrato que vincula a las partes es indispensable para

${ }^{22}$ Sobre este particular vid. STJCE 16 septiembre 2008, Sot. Lélos Kai Sia/GlaxoSmithKline, asuntos acumulados C-468/06 a C-478/06, ECLI:EU:C:2008:504, apartado 77.

${ }^{23}$ Conclusiones del Abogado General Sr. H. Saugmandsgaard Øe, presentadas el 10 de septiembre de 2020. Wikingerhof GmbH \& Co. KG contra Booking.com BV, ECLI:EU:C:2020:688, apartado 55.

${ }^{24}$ Conclusiones del Abogado General Sr. H. Saugmandsgaard Øe, presentadas el 10 de septiembre de 2020. Wikingerhof GmbH \& Co. KG contra Booking.com BV, ECLI:EU:C:2020:688, apartado 56. Sobre este particular vid. también, O. GouT, "Le cumul des responsabilités contractuelle et extracontractuelle en droit belge en droit franÇais: de la genèse des règles aux perspectives d'evolution, en E. VAN DEN HAUTE, Le droit des obligations dans les jurisprudences française et belge, Bruylant, Bruselas, 2013, pp. 123-146.

${ }^{25}$ STS 6 octubre 1992, $\mathrm{n}^{\circ}$ 7542/1992, ECLI:ES:TS:1992:7542, FD $3^{\circ}$.

${ }^{26}$ Conclusiones del Abogado General Sr. H. Saugmandsgaard Øe, presentadas el 10 de septiembre de 2020. Wikingerhof GmbH \& Co. KG contra Booking.com BV, ECLI:EU:C:2020:688, apartados 61 y 78-79.

${ }^{27}$ S. ZoG, "Accumulation of contractual"..., p. 62; Conclusiones del Abogado General Sr. H. Saugmandsgaard Øe, presentadas el 10 de septiembre de 2020.Wikingerhof GmbH \& Co. KG contra Booking.com BV, ECLI:EU:C:2020:688, apartado 61. 
determinar la licitud o ilicitud del comportamiento que se le reprocha al demandado ${ }^{28}$. Por el contrario, si el demandante invoca normas de responsabilidad civil y no es indispensable el análisis del contrato para determinar el carácter lícito o ilícito de ese comportamiento, la obligación podría calificarse como "delictual” en atención al R. Bruselas I bis ${ }^{29}$.

18. Esta solución implica varios aspectos a tener en cuenta:

1) No son posibles las competencias accesorias. El juez de lo contractual no va a poder conocer de las cuestiones delictuales ${ }^{30}$. Existe un juez competente para cada pretensión, no prevalece el foro contractual (art. 7.1) frente al delictual (art. 7.2). Aunque hay doctrina que así lo ha considerado $^{31}$, la realidad es que conforme está redactado el actual R. Bruselas I bis no es posible debido a que atribuir competencias en materia delictual al juez del contrato sería ampliar el ámbito de aplicación del art. 7.132.

2) La fragmentación de litigio. Si la acción no se califica en global, hay un fragmentación del litigio. Esto quiere decir que las pretensiones contractuales serán resultas por el "juez del contrato" (art. 7.1) y que las de responsabilidad civil extracontractual por "el juez del delito" (art. 7.2). En ocasiones, estos jueces pueden coincidir en un mismo Estado, en otras no. El resultado es una dispersión del pleito Esto presenta aspectos positivos y negativos. Lo positivo a la hora de interpretar las competencias especiales del R. Bruselas I bis (arts. 7.1 y 7.2) de este modo es que se asegura la previsibilidad y la seguridad jurídica. Y esto además, tiene un impacto directo en el resto del Derecho internacional privado europeo, en especial afecta a la relación entre el Reglamento Roma I y el Reglamento Roma II. El aspecto negativo es que se lesiona la buena administración de justicia debido a que los costes del litigio aumentan considerablemente por esa posible dispersión del pleito. Sin embargo, este problema tiene una solución fácil de llevar a cabo y es que el demandante puede interponer la demanda ante los tribunales del domicilio del demandado ${ }^{33}$. Los cuales podrían conocer de todas las pretensiones, de las que tienen una naturaleza contractual pero también de las extracontractuales.

3) La importancia del Derecho material que se invoca por el demandante. Esa labor de calificación para enmarcar la pretensión en el art. 7.1 o en el art. 7.2, y así precisar la causa en la que se basa la acción, va a depender en cierto modo en las normas materiales que invoque el demandante. A pesar de que la pretensión no se califica en atención al Derecho aplicable ${ }^{34}$, ya que en esa fase el juez todavía no lo ha determinado ${ }^{35}$. El Derecho material que invoca el demandante tiene más importancia de lo que se podría pensar en un primer momento. Ese Derecho material en el que se fundamenta la demanda facilita la labor del juez a la hora de calificar las pretensiones de forma autónoma en atención al R. Bruselas I $b i s^{36}$. En definitiva, ese Derecho material en el que se basa la acción aunque no es determinante da pistas al juez en relación a qué tipo de obligación ha podido incumplir el demandado.

4) La necesidad de interpretar el contrato en algún momento no obsta para que la calificación deba seguir siendo delictual. El hecho de que el contrato deba interpretarse en alguna de las

${ }^{28}$ STJUE 24 noviembre 2020, Wikingerhof v. Booking, C- 59/19, ECLI:EU:C:2020:950, apartado 32. Anteriormente, STJUE de 13 de marzo de 2014, Brogistter, C-548/12, ECLI:EU:C:2014:148, apartado 25.

${ }^{29}$ STJUE 24 noviembre 2020, Wikingerhof v. Booking, C- 59/19, ECLI:EU:C:2020:950, apartado 33.

${ }^{30}$ STJCE 27 septiembre 1988, Kalfelis, C-189/87, ECLI:EU:C:1988:459, apartado 19.

${ }^{31}$ A. Briggs, Civil Jurisdiction and Judgments, Informa Law from Routledge, Oxford, 2015, p. 237.

${ }^{32} \mathrm{Vid}$. sobre este particular vid. S. ZoG, “Accumulation of contractual”..., p. 49 y 61.También en el mismo sentido las Conclusiones del Abogado General Sr. H. Saugmandsgaard Øe, presentadas el 10 de septiembre de 2020. Wikingerhof GmbH \& Co. KG contra Booking.com BV, ECLI:EU:C:2020:688, apartados 115.

${ }^{33}$ STJCE 27 septiembre 1988, Kalfelis, C-189/87, ECLI:EU:C:1988:459, apartado 20.

${ }^{34}$ S. ZoG, “Accumulation of contractual”..., p. 40; STJUE 7 junio 1002, Handte, C-26/91, ECLI:EU:C:1992:268, apartado 10

${ }^{35}$ Conclusiones del Abogado General Sr. H. Saugmandsgaard Øe, presentadas el 10 de septiembre de 2020.Wikingerhof GmbH \& Co. KG contra Booking.com BV, ECLI:EU:C:2020:688, apartados 62.

${ }^{36}$ Ibidem. 
fases del análisis de la responsabilidad extracontractual no significa que la obligación que se imputa al demandado tenga que calificarse como contractual. Esto puede materializarse ad ex. cuando en determinados supuestos de responsabilidad por daños es necesario resolver una cuestión previa que tiene que ver con la relación contractual de las partes. La existencia de esa cuestión previa de naturaleza contractual no implica que la cuestión principal que se persigue resolver deba también calificarse en el mismo sentido ${ }^{37}$. Lo mismo sucede cuando el demandando que se enfrente a una acción donde se le reclaman daños alega un contrato como base para su defensa. El hecho de que alegue la existencia de un contrato no obsta para que la obligación en la que se fundamenta la acción pueda seguir calificándose como delictual en virtud del art. 7.2 del R. Bruselas I bis ${ }^{38}$.

\section{La prueba que debe realizar el demandante}

19. Un aspecto que surge a los inicios de la litigación transfronteriza es qué aspectos debe probar el demandante cuando decide interponer su demanda en virtud del art. 7.1 o 7.2 del R. Bruselas I bis.

20. En primer lugar, tanto desde la perspectiva de ambos preceptos el estándar de prueba mínimo se aprecia en atención al Derecho procesal del foro ${ }^{39}$

21. Desde la perspectiva del art. 7.1, se tendría que probar la disputa está relacionada con un contrato. Sin embargo, no es necesario probar la existencia de un contrato concreto entre las partes ${ }^{40}$. De hecho, ni la alegación de que no existe un contrato impide que se aplique el art. 7.1 del R. Bruselas I $b i s^{41}$. De este modo, un juez podrá declararse competencia mediante el foro contractual del art. 7.1 cuando las partes le prueben que existen una disputa pendiente sobre aspectos que afectan a su relación contractual.

22. En atención al art. 7.2, precisar que el demandante que se decide litigar en atención al citado foro del R. Bruselas I bis no tiene que probar el daño antes o al momento de presentar la demanda ${ }^{42}$. La existencia del daño y que por lo tanto sea indemnizable depende de la Ley que se aplique al fondo del asunto la cual se determina mediante la aplicación de la correspondiente norma de conflicto. Así, el demandante deberá aportar un "principio de prueba". Es decir, unos indicios que permitan al juez apreciar si concurre o no el foro delictual sin tener en cuenta Derecho nacional alguno ${ }^{43}$. Por lo tanto, que el juez se declare competente en materia de responsabilidad extracontractual en atención al art. 7.2 no significa que esté reconociendo un daño que debe ser indemnizado. De este modo, si al interponer la demanda no se debe probar el daño cabe preguntarse qué debe probarse.

Pues bien el demandante debería dejar constancia en la interposición de la demanda dos aspectos ${ }^{44}$ :

1) El daño ha tenido lugar. No obstante, el demandante también puede ejercitar el art. 7.2 si lo que persigue es una declaración de que no existe responsabilidad extracontractual por su parte debido a que el daño no ha existido ${ }^{45}$.

\footnotetext{
${ }^{37}$ Conclusiones del Abogado General Sr. H. Saugmandsgaard Øe, presentadas el 10 de septiembre de 2020.Wikingerhof GmbH \& Co. KG contra Booking.com BV, ECLI:EU:C:2020:688, apartados 104.

${ }^{38}$ STJCE 4 marzo 1982 ,Effer, as. 38/81, ECLI:EU:C:1982:79, apartado 7.

${ }^{39}$ STJCE 7 marzo 1995, Shevil, C-68/93, ECLI:EU:C:1995:61, apartado 36.

${ }^{40}$ S. ZoG, "Accumulation of contractual"..., p. 54.

${ }^{41}$ STJCE 4 marzo 1982 ,Effer, as. 38/81, ECLI:EU:C:1982:79, apartado 8.

${ }^{42}$ En la doctrina, A.L. Calvo Caravaca/J. Carrascosa GonzÁlez, Tratado de Derecho Internacional privado, tomo III, Tirant lo Blanch, 2020, p. 945. En la jurisprudencia, STJUE 25 octubre 2012, Folien Fischer y Fofitec, C-133/11, EU:C:2012:664, apartado 50.

${ }^{43}$ STJUE 28 enero 2015, Kolassa, C-375/13, ECLI:EU:C:2015:37, apartado 62; STJUE 16 junio 2016, Universal, C-12/15, ECLI:EU:C:2016:449, apartado 44.

${ }^{44}$ A.L. Calvo Caravaca/J. Carrascosa González, Tratado de Derecho..., p. 945.

${ }^{45}$ Vid. STJUE 25 octubre 2012, Folien Fischer y Fofitec, C-133/11, EU:C:2012:664, apartado 52. Para un mayor detalle,
} 
2) El daño ha ocurrido en un concreto Estado miembro. Esto es necesario debido a que el foro del citado art. 7.2 otorga competencia judicial internacional pero también territorial al tribunal del lugar donde se ha producido o pueda producirse el hecho litigioso y éste no puede ser otro lugar que un Estado miembro.

23. En conclusión, en una disputa internacional donde existen hechos que pueden generar responsabilidad de diferente naturaleza, contractual y extracontractual, es clave quien inicia la demanda y cómo plantea y fundamenta el litigio. El demandante tiene en su poder una baza importante y es que ostenta conforme se han ido interpretando los foros especiales en materia contractual y delictual por el TJUE una gran capacidad para perfilar el asunto y que se considere bien un asunto "en materia contractual" o "en materia delictual" en atención al R. Bruselas I bis.

\section{Acciones paralelas y litispendencia}

24. A lo largo del trabajo hemos señalado que en atención al fundamento y causa de la demanda, ésta se calificará como "contractual" o "delictual/extracontractual" en atención al R. Bruselas I bis. Como también hemos precisado esto significa que pueda existir un juez que conozca únicamente "de lo contractual" y otro que conozca de los aspectos "delictuales/extracontractuales" que enfrentar a las mismas partes. Sin embargo, ante esta avocación irremediable a la apertura de diferentes litigios en distintos Estados miembros cabe plantearse si podría el demandado alegar litispendencia (art. 29 R. Bruselas I bis). Esto permitiría el litigio sólo pudiera dirimirse ante un único tribunal. Es decir, el tribunal ante el que se interpuso la demanda en primer lugar, ya que el mecanismo para resolver la litispendencia en atención al art. 29 del R. Bruselas I bis es el orden cronológico en el que las demandas se interpusieron ante los tribunales ${ }^{46}$.

25. La respuesta a este cuestión es no. La litispendencia tiene lugar en atención al art. 29 del R. Bruselas I bis cuando dos litigios afectan a las mismas partes, tienen la misma causa y el mismo objeto. Así, en este tipo de demandas hay que tener en cuenta que los hechos podrían ser los mismos pero el problema jurídico no se resuelve conforme a las mismas normas debido a que tanto los objetos como las causas de las demandas son diferentes.

Esta respuesta se debe entender teniendo presente lo siguiente:

1) El concepto de litispendencia del art. 29 del R. Bruselas I bis es europeo resultando el Derecho nacional de los Estados miembros irrelevante ${ }^{47}$.

2) Hay que atender a la interpretación europea de "mismas partes", "misma causa" y "mismo objeto". El TJUE ha entendido que "mismas partes" son mismas personas, con independencia de cual sea su domicilio y donde se encuentre éste o la posición procesal que ocupan en el litigio ${ }^{48}$.

En relación al aspecto de "misma causa" se entiende esa identidad cuando los litigios se basan en los mismos hechos y se invocan las mismas normas jurídicas ${ }^{49}$. En otras palabras, cuando las demandas tienen el mismo origen jurídico ${ }^{50}$.

\footnotetext{
vid. P. Mankowski, “art.7”, en U.Magnus/.P.Mankowski, European Commentaries on Private International Law. Brussels I bis Regulation, vol. 1, Ottoschmidt, 2016, pp. 263-267.

${ }^{46}$ STJUE 4 mayo 2017,HanseYachts, C-29/16, ECLI:EU:C:2017:343, apartado 28. Para un comentario sobre esta sentencia vid. $\mathrm{M}^{\mathrm{a}}$. A. Rodríguez VÁzQuez, "Litispendencia y diligencias de prueba. Algunas reflexiones sobre la sentencia del TJUE de 4 de mayo de 2017", CDT, vol. 10, no 1, pp. 630-638.

${ }^{47}$ STJCE 8 diciembre 1987, Gubisch, 144/86, ECLI:EU:C:1987:528, apartado 14.

${ }^{48}$ STJCE 27 junio 1991, Overseas Union Insurance, C- 351/89, ECLI:EUC:1991:279.

${ }^{49}$ STJCE 6 diciembre 1994, Tatry, C-406/92, ECLI:EU:C:1994:400, apartado 39.

${ }^{50}$ A.L. Calvo Caravaca/J. Carrascosa González, Tratado de Derecho..., p. 1278.
} 
Por su parte, el alto Tribunal europeo ha considerado que "mismo objeto" se debe apreciar en atención a "la finalidad de la demanda" ${ }^{2}$. A su objetivo. Así, es irrelevante cómo se denominen los procedimientos en los Estados miembros donde se ejerciten las acciones. La clave para identificar cuáles son los objetos de las demandas es identificar los aspectos sustanciales que se reclaman ${ }^{52}$.

Se puede afirmar que el TJUE ha seguido un concepto amplio de objeto, ya que se puede incluir dentro del mismo una acción que persigue que se cumpla un contrato y otra que persigue su nulidad ${ }^{53}$.

No obstante, es muy importante apreciar el objeto de la demanda en el caso particular concreto debido a que sobre lo que se entiende por "objeto" ha habido importantes discrepancias doctrinales. De hecho, existe un sector doctrinal que entiende que el art. 29 R. Bruselas I bis sólo podría aplicarse cuando los litigios tienen objetos idénticos ${ }^{54}$. No compartiendo la visión amplia que establece el TJUE.

26. Desde nuestro punto de vista, cuando se ejercita una acción en un tribunal de un Estado miembro y los fundamentos se basan en responsabilidad contractual, mientras que en otro tribunal de otro Estad miembro, los fundamentos están basados en la responsabilidad por daños, la finalidad de la demanda difiere. El objeto de ambos procesos no es el mismo, no siendo relevante los fundamentos de defensa del demandado ${ }^{55}$. De este modo, por coherencia los dos procesos deben seguir en paralelo. Si no fuera así y sólo se pudiera declarar competente el "juez de lo contractual" o "el juez de lo delictual", es decir, el juez ante el que se interpone la primera demanda, esto implicaría que habría cuestiones que quedarían sin resolver. Como se ha sostenido en el presente trabajo, el "juez de lo contractual" no puede conocer en base al art. 7.1 de los aspectos delictuales ni "el juez de lo delictual" puede conocer de las cuestiones contractuales. La admisión de la litispendencia en estos casos implicaría denegación de justicia ${ }^{56}$. Además, no hay que olvidar que el fin de la litispendencia es evitar litigios paralelos que tengan como resultado resoluciones contradictorias. En este tipo de acciones no se tendría que tener miedo a ese efecto contradictorio ya que las causas de las demandas son diferentes.

\section{Conclusiones}

27. La sentencia objeto de comentario es una sentencia relevante desde la perspectiva de la litigación transfronteriza en materia de daños por infracción del Derecho de la competencia. Esto es así porque es una sentencia que permite acudir al tribunal del lugar donde se ha producido el daño por infringir la competencia, aunque las partes estén vinculadas por un contrato. Esto es una cuestión importante para las pequeñas empresas que se relacionan con grandes plataformas electrónicas como Booking o Amazon. Si los perjudicados por daños por infringir la competencia basan el fundamento de su demanda en una vulneración del Derecho antitrust, esta acción se puede calificar como materia "delictual/ extracontractual"en atención al art. 7.2 del R. Bruselas I bis, y por tanto se puede presentar la demanda ante el tribunal del lugar donde se produce o se pudiera haber producido el daño, lugar que suele coincidir con el domicilio de la víctima. Un tribunal que a la víctima le podría resultar más próximo para reclamar daños que acudir al foro del domicilio del demandado (art. 4 R. Bruselas I bis).

28. A nuestro juicio, de esta sentencia se pueden extraer las siguientes conclusiones:

1) $\mathrm{El}$ art. $7.1 \mathrm{y}$ el art. 7.2 no prevalecen, son foros alternativos, no pudiendo el juez competente vía art. 7.2 conocer de aspectos contractuales. Las competencias accesorias no son posible en virtud de estos foros.

\footnotetext{
${ }^{51}$ STJCE 6 diciembre 1994, Tatry, C-406/92, ECLI:EU:C:1994:400, apartado 41.

${ }^{52}$ R. Fentiman, "art. 29", en U.Magnus/.P.Mankowski, European Commentaries on Private International Law. Brussels I bis Regulation, vol. 1, Ottoschmidt, 2016, p. 730.

${ }^{53}$ STJCE 8 diciembre 1987, Gubisch, 144/86, ECLI:EU:C:1987:528, apartado 19.

${ }^{54}$ R. Fentiman, “art. 29”, en ...p. 731.

${ }^{55}$ STJCE 8 mayo 2003, Gatner Electronic, C-111/01, ECLI:EU:C:apartado 32; STJUE 14 octubre 2004, Mcersk Olie \& Gas, C-39/02, ECLI:EU:C:2004:515, apartado 36.

${ }^{56} \mathrm{Vid}$. S. ZoG, “Accumulation of contractual"..., p. 65.
} 
2) La calificación de la obligación que sirve de basa a la demanda se debe calificar de forma autónoma y esta calificación es lo que permite al juez declararse competente bien mediante el art. $7.1 \mathrm{o}$ el art. 7.2.

3) El demandante debe tener muy claro cual es el fundamento de su demanda, ya que su actuación juega un papel fundamental en la determinación de la competencia. Así, debe tener presente que la acción se puede seguir calificando de extracontractual en atención al art. 7.2 R. Bruselas I bis, con independencia de que el demandado alegue la existencia de un contrato y que ambas partes están vinculadas por el mismo. 